\title{
Locke on Persons and Other Kinds of Substances
}

(Penultimate draft. Forthcoming in Pacific Philosophical Quarterly. Please cite the published version.)

Matthew A. Leisinger

\begin{abstract}
Locke's commentators are divided about whether Locke thinks that the idea of a person is a substance-idea or a mode-idea. I use Locke's theory of kinds to argue for an intermediate interpretation on which the idea of a person is a substance-idea that contains a mode-idea. As a result, while proponents of the substance interpretation correctly claim that 'person' designates a kind of substance, proponents of the mode interpretation are nonetheless correct in insisting that mode-ideas play an important role in Locke's account of persons and personal identity.
\end{abstract}

In Chapter 12 of Book 2 of An Essay concerning Human Understanding, Locke distinguishes three kinds of complex ideas. ${ }^{1}$ Locke calls them 'substances', 'modes', and 'relations', but I will call them 'substance-ideas', 'mode-ideas', and 'relation-ideas' so as to avoid any ambiguity between ideas and their objects. He goes on in subsequent chapters to catalog the various complex ideas that fall under each of these headings. Chapter 27 of Book 2, entitled 'Of Identity and Diversity', officially concerns the complex idea of identity, which Locke takes to be a relation-idea. 2.27 is more famous, however, for Locke's discussion of personal identity in particular and, as a result, for his discussion of the idea of a person.

Unfortunately, Locke never says what kind of complex idea he takes the idea of a person to be. As a result, commentators disagree about whether Locke thinks that the idea of a person is a substance-idea or a mode-idea. ${ }^{2}$ The chief difference between substance-ideas and mode-ideas is that, whereas substance-ideas 'represent distinct particular things subsisting by themselves' (2.12.6), modeideas are 'such complex Ideas, which however compounded, contain not in them the supposition of 
subsisting by themselves, but are considered as Dependences on, or Affections of Substances' (2.12.4). So, whereas Locke's standard examples of substance-ideas include the ideas of a man or a horse (2.23.3), his examples of mode-ideas include the ideas of gratitude or murder (2.12.4), entities that exist only insofar as they are instantiated in particular substances - murder, for example, requires both a murderer and a murdered. ${ }^{3}$ Commentators thus disagree about whether Locke thinks that the idea of a person is the idea of a self-subsistent being like a man or a horse, or whether he instead thinks that it is the idea of a dependent being like gratitude or murder.

One of my goals in this paper will be to argue in favour of the substance interpretation and against the mode interpretation. Locke's view, I will claim, is that the idea of a person is a substanceidea and not a mode-idea. Before entering this debate, however, we need to clear up some potential confusions. First, commentators often fail to distinguish the question of whether Locke thinks that the idea of a person is a substance-idea or a mode-idea from the question of whether Locke thinks that persons are substances or modes. These two questions are easily conflated, especially since Locke himself often uses the language of things when he ought to use the language of ideas (and vice versa). In this paper, I am going to focus my attention on the first of these questions. Strictly speaking, Book 2 of the Essay ('Of Ideas') is concerned primarily not with what exists but with our ideas of what exists. It is one of Locke's tasks in Book 4 ('Of Knowledge and Opinion') to consider how much we can learn about the former from the latter. Admittedly, Locke does often appear to mix metaphysics and psychology in Book $2 .{ }^{4}$ Indeed, his discussion of persons in 2.27 is cast almost entirely in the language of things rather than in the language of ideas. In this paper, however, I want to bracket these complications by setting aside the ontological status of persons and focusing instead on our ideas.

A second confusion arises from the fact that the phrase 'the idea of a person' is ambiguous between the general idea of person and the idea of an individual person. Whereas the former is the idea of a kind of being, the latter is the idea of a particular being at a particular time and in a particular place - 
for example, Socrates on a Sunday morning strolling through the agora (see 3.3.6). ${ }^{5}$ We thus need to distinguish two further questions. First, is the general idea of person the idea of a kind of substance or is it instead the idea of a kind of mode? Second, is the idea of an individual person the idea of an individual substance or is it instead the idea of an individual mode? I am going to focus on the first of these questions, in part because Locke's own discussion of substance focuses on kinds rather than individuals. What I say about the first question will, I take it, have significant implications for the second, but I will not discuss these implications here. Accordingly, my claim will be that, for Locke, the general idea of person is the idea of a kind of substance.

A third confusion arises from the distinction between substance-ideas and mode-ideas. While I am going to argue that the general idea of person is a substance-idea, I am also going to argue that most if not all substance-ideas are actually composed of both substance-ideas and mode-ideas. This point is easily overlooked as Locke often emphasizes the contrast between substance-ideas and modeideas, but it has significant consequences for how we ought to understand the general idea of person. If substance-ideas can contain mode-ideas, then the difference between the substance interpretation and the mode interpretation may be less significant than most commentators assume. Whereas proponents of the mode interpretation hold that the general idea of person is a mode-idea, a proponent of the substance interpretation may - and, I will argue, should - hold that the general idea of person is a substance-idea that nonetheless contains a mode-idea.

I thus have two goals in this paper, one more narrow and the other more broad. My narrower goal is to argue for the substance interpretation and against the mode interpretation. My broader goal, however, is to take a closer look at Locke's account of ideas of kinds of substances and to use this account to illuminate the nature of the debate between the substance interpretation and the mode interpretation. Locke's view, I will argue, is that ideas of what I will call 'non-basic' kinds of substances are composed of both substance-ideas and mode-ideas. Moreover, I will argue that mode-ideas play a 
crucial role in Locke's theory of identity because he holds that the diachronic identity conditions for non-basic kinds of substances are determined by the mode-ideas that they contain. As a result, while I will argue that the general idea of person is a substance-idea, I think that proponents of the mode interpretation are nonetheless correct to insist that mode-ideas play a crucial role in Locke's theory. They play this role, however, not because the general idea of person itself is a mode-idea but rather because it contains a mode-idea.

\section{Oaks, Masses, and Identity}

My plan is to use Locke's theory of kinds to clarify and argue for the substance interpretation. Prima facie, however, what Locke says about ideas of kinds of substances in 2.27 might seem to count against rather than for the substance interpretation. Early in that chapter, Locke says that 'We have the Ideas but of three sorts of Substances; 1. God. 2. Finite Intelligences. 3. Bodies' (2.27.2). Notably, this list does not include the general idea of person. Locke then goes on to argue that sameness of substance is neither necessary nor sufficient for sameness of person, which again seems to imply that the general idea of person is not the idea of a kind of substance. ${ }^{6}$

Closer scrutiny complicates this reading, however. The problem is that similar observations might be used to argue that the general idea of oak, for example, is not the idea of a kind of substance. ${ }^{7}$ Locke does not list the general idea of oak in 2.27 .2 as one of our three ideas of different kinds of substances. Moreover, Locke goes on in 2.27.4-5 to argue that sameness of substance is neither necessary nor sufficient for sameness of oak. And yet, Locke makes it clear elsewhere in the Essay that the general idea of oak is indeed the idea of a kind of substance. When Locke presents his official account of ideas of kinds of substances in Book 2 Chapter 23 ('Of our Complex Ideas of Substances'), he says that 'the Ideas of a Man, Horse, Gold, Water, etc.' are the ideas of so many different kinds of substances (2.23.3). A longer list may be extracted from Book 3 Chapter 6 ('Of the Names of Substances'), where Locke's examples include the ideas of gold (3.6.2), man (3.6.3), horse, mule, animal, herb (3.6.7), 
lead, antimony, wood, stone (3.6.9), lily, rose, sheep, goat (3.6.9), fish, bird, amphibian, seal, porpoise, (3.6.12), and so on. If these are all ideas of different kinds of substances, then it is hard to believe that the general idea of oak is not also the idea of a kind of substance. ${ }^{8}$

These reflections suggest a natural path forwards. Locke’s discussion in 2.27 appears prima facie to imply that neither the general idea of person nor the general idea of oak is the idea of a kind of substance. We have strong independent evidence, however, for thinking that Locke does in fact take the general idea of oak to be the idea of a kind of substance. So, if we want more fully to understand Locke's position in 2.27 , we can begin by thinking more carefully about what Locke says about oaks. In this section, I am going to examine Locke's discussion of oaks in 2.27.3-4. I will argue that, on the most plausible reading of these passages, Locke's view is that the general idea of oak is indeed the idea of a kind of substance. I will then go on in section 2 to offer an interpretation of Locke's theory of kinds that explains why Locke sometimes seems to suggest otherwise in 2.27. Finally, with this interpretation of Locke's theory of kinds in hand, I will return the general idea of person in section 3.

Locke's discussion of oaks in 2.27.3-4 occurs in the context of a broader discussion of identity. Locke's main goal in 2.27.1-7 is to give a general account of the diachronic identity conditions of different kinds of beings, or to explain what it is for a being of kind $\mathrm{F}$ at $\mathrm{t}_{1}$ to be identical to a being of kind $\mathrm{F}$ at $\mathrm{t}_{2}$. His central contention is that different kinds of beings have different diachronic identity conditions. What it is for a man to persist, for example, may be different from what it is for a person to persist. Accordingly, he argues that, in order to determine whether a being at one time is identical to a being at another time, we must pay careful attention to the kind of being with which we are concerned. In Locke's words, in order 'to conceive, and judge of [identity] aright, we must consider what Idea the Word it is applied to stands for' (2.27.7).

Locke begins his discussion with the case of simple substances. While he has just said in 2.27.2 that we have the ideas of three kinds of substances ('1. God. 2. Finite Intelligences. 3. Bodies.'), he 
discusses only simple bodies in 2.27.3. ${ }^{9}$ Locke argues that, since a simply body or 'Atom' is 'a continued body under one immutable Superficies, existing in a determined time and place', it follows that 'it is the same, and so must continue, as long as its Existence is continued: for so long it will be the same, and no other' (2.27.3). Commentators standardly explain the 'continued existence' that Locke discusses in this passage as a kind of spatiotemporal continuity: an atom at one time is identical to an atom at another time just in case the earlier atom is spatiotemporally continuous with the later atom. ${ }^{10}$ Locke goes on to extend this account from simple bodies to compound bodies or 'Masses' (aggregates of atoms), arguing that the diachronic identity of a mass is reducible to the diachronic identity of its constituent atoms. So long as the atoms that compose a mass continue to exist 'united together', without gaining any new atoms or losing any old atoms, so too does the mass. Locke is thus a mereological essentialist about masses: a mass at one time is identical to a mass at another time just in case every atom in the earlier mass is spatiotemporally continuous with some atom in the later mass and vice versa.

Locke then turns from simple and compound bodies to organisms:

An Oak, growing from a Plant to a great Tree, and then lopp'd, is still the same Oak: And a Colt grown up to a Horse, sometimes fat, sometimes lean, is all the while the same Horse: though, in both these Cases, there may be a manifest change of the parts [...]. (2.27.3)

This passage demonstrates Locke's central contention that different kinds of beings have different diachronic identity conditions. A mass, Locke thinks, cannot survive even the tiniest variation in its constituent atoms. A living organism such as an oak or a horse, by contrast, can survive even some very significant variations. Why is it that oaks, unlike masses, can survive changes in their parts? Locke's answer is that oaks and masses are different kinds of beings and that different kinds of beings can have different diachronic identity conditions.

What exactly is the crucial difference between oaks and masses that yields such a significant difference in their diachronic identity conditions? Here is one tempting answer. ${ }^{11}$ If a mass is a 
compound substance, then perhaps an oak is a mode that depends upon the particular mass in which it is realized. Locke himself seems to suggest such a view in the next section when he says that, whereas a mass is 'the Cohesion of Particles of Matter any how united', an oak is a certain 'disposition of [those Particles of Matter]', namely, such a disposition or 'Organization of those parts, as is fit to receive, and distribute nourishment, so as to continue, and frame the Wood, Bark, and Leaves, etc. of an Oak' (2.27.4). Prima facie, Locke's claim here might seem to be that, whereas a mass is a collection of atoms (a compound substance), an oak is something like the functional organization of those atoms, a mode that is realized in that collection of atoms.

One virtue of this interpretation is that it provides a clear answer as to why a mass and an oak have different diachronic identity conditions. A mass is an aggregate of atoms. So, if a mass gains or loses even a single atom, it is no longer the same mass and therefore goes out of existence. An oak, by contrast, is the functional organization of an aggregate of atoms. Since the same functional organization can be realized in a succession of numerically distinct masses, it follows that an oak can survive changes that a mass cannot.

Despite its initial appeal, however, this interpretation faces serious challenges. First of all, it is worth emphasizing how surprising it would be if Locke did in fact hold in 2.27 that oaks are modes. As we saw earlier, Locke's view elsewhere in the Essay is that beings like oaks - men, horses, roses, gold, and so on - are substances. Why should Locke adopt a different view in 2.27? If Locke does indeed hold in 2.27 - and only in 2.27 - that oaks are modes rather than substances, he would be guilty of a fairly striking inconsistency.

Second, and more importantly, a close reading of the text does not bear out this interpretation. Here, again, is the relevant passage (in slightly greater length):

We must therefore consider wherein an Oak differs from a Mass of Matter, and that seems to me to be in this; that the one is only the Cohesion of Particles of Matter any how united, the other such a disposition of them as constitutes the parts of an Oak; and such an Organization 
of those parts, as is fit to receive, and distribute nourishment, so as to continue, and frame the Wood, Bark, and Leaves, etc. of an Oak, in which consists the vegetable Life. (2.27.4)

Locke makes two key claims in this passage. His first claim is that a mass is 'the Cohesion of Particles of Matter any how united'. There is something odd about Locke's phrasing here. On a superficial reading, his phrasing might suggest that a mass is not a collection of particles but rather the cohesion of a collection of particles. Locke seems prima facie to be claiming that the mass is a mere mode, namely, the mode of 'Cohesion' that is realized in a collection of particles. This interpretation is obviously mistaken, however. We understand quite well what Locke means to claim. Clearly, his claim is that a mass is not the cohesion of particles but rather the particles thus cohering. A mass, in other words, is just a collection of particles that cohere together in a certain way. Turn now to Locke's second claim: an oak is 'the disposition of [those Particles] as constitutes the parts of an Oak'. Prima facie, Locke's claim might seem to be that an oak is a mere mode, namely, the 'disposition' that is realized in a collection of particles. Notice, however, that this is exactly the kind of interpretation that we rejected with respect to Locke's first claim. Clearly, a mass is not the cohesion of particles but rather the particles thus cohering. So, given our interpretation of the first claim, it seems that we are under some pressure to give parallel interpretation of the second claim: an oak is not the disposition of particles but rather the particles thus disposed. On this interpretation, Locke's claim is not that an oak is a mere mode, the functional organization or 'disposition' of a collection of particles. Instead, his claim is that an oak is a collection of particles in which such a functional organization or 'disposition' is realized.

Locke's subsequent discussion bears out this alternative interpretation. At the end of the passage quoted above, Locke identifies the 'Organization' of the parts of the oak with the oak's 'vegetable Life'. He goes on:

That being then one Plant, which has such an Organization of Parts in one coherent Body, partaking of one Common Life, it continues to be the same Plant, as long as it partakes of the same Life, though that Life be communicated to new Particles of Matter vitally united to the living Plant, in a like continued Organization, conformable to that sort of Plants. (2.27.4) 
In this passage, Locke clearly distinguishes the oak itself from its vegetable life. The oak itself is not the functional organization of its constituent parts. Instead, Locke identifies this functional organization with the oak's vegetable life. Since the oak itself is not the functional organization of its constituent parts, there is little reason to think that the oak itself is a mere mode. Instead, it is the oak's vegetable life that is a mode. More specifically, the oak's vegetable life is that mode in virtue of which this particular collection of particles is organized in such a way as to form an oak. ${ }^{12}$

Despite distinguishing the oak from its vegetable life, the oak's vegetable life nonetheless plays a crucial role in Locke's subsequent account of the oak's diachronic identity:

For this Organization being at any one instant in any one Collection of Matter, is in that particular concrete distinguished from all other, and is that individual Life, which existing constantly from that moment both forwards and backwards in the same continuity of insensibly succeeding Parts united to the living Body of the Plant, it has that Identity, which makes the same Plant, and all the parts of it, parts of the same Plant, during all the time that they exist united in that continued Organization, which is fit to convey that Common Life to all the Parts so united. (2.27.4)

Suppose that there is a mass $\mathrm{M}_{1}$ at $\mathrm{t}_{1}$ and a mass $\mathrm{M}_{2}$ at $\mathrm{t}_{2} . \mathrm{M}_{1}$ is spatiotemporally continuous with $\mathrm{M}_{2}$; that is, there is a spatiotemporally continuous series of masses linking $M_{1}$ at $t_{1}$ with $M_{2}$ at $t_{2}$. $M_{1}$ is not numerically identical to $\mathrm{M}_{2}$, however, because, sometime between $\mathrm{t}_{1}$ and $\mathrm{t}_{2}, \mathrm{M}_{1}$ gains or loses at least one atom. Nonetheless, the constituent atoms of $\mathrm{M}_{1}$ possess a certain functional organization or vegetable life $\mathrm{V}_{1}$ in virtue of which the constituent atoms of $\mathrm{M}_{1}$ are organized in such a way as to 'frame the Wood, Bark, and Leaves, etc. of an Oak'. Likewise, the constituent atoms of $\mathrm{M}_{2}$ also possess such a vegetable life $\mathrm{V}_{2}$. Moreover, $\mathrm{V}_{1}$ is spatiotemporally continuous with $\mathrm{V}_{2}$; that is, there is a spatiotemporally continuous series of masses linking $\mathrm{M}_{1}$ and $\mathrm{M}_{2}$ each of which possesses the functional organization of an oak. Therefore, while $\mathrm{M}_{1}$ is not identical to $\mathrm{M}_{2}, \mathrm{~V}_{1}$ is identical to $\mathrm{V}_{2} \cdot{ }^{13}$ While the original mass $\mathrm{M}_{1}$ has gone out of existence and has been replaced by $\mathrm{M}_{2}$, the vegetable life that was realized in $\mathrm{M}_{1}$ has not gone out of existence but continues to be realized in $\mathrm{M}_{2}$. In Locke's words, the vegetable life exists 'constantly from that moment both forwards and backwards in the same continuity 
of insensibly succeeding Parts'. Now, here is the crucial move: Locke's view is that the oak itself continues to exist precisely in virtue of the fact that its vegetable life continues to exist. Of course, the oak itself is not identical to its vegetable life. Nonetheless, the oak's diachronic identity is determined by the diachronic identity of its vegetable life. This is why Locke says that, so long is the vegetable life continues to exist, 'it has that Identity, which makes the same Plant, and all the parts of it, parts of the same Plant'. Locke's thought here is that the oak's vegetable life is what unifies the oak's constituent parts and makes them parts of a single oak, both at a time and over time. It is because the constituent parts of the oak possess the functional organization of this vegetable life that they are parts of an oak, and it is because each new mass in the spatiotemporally continuous series of numerically distinct masses possesses the functional organization of this vegetable life that the parts of each new mass form the same oak over time.

This account of the oak's diachronic identity merely exacerbates our earlier question about the oak's ontological status, however. At any given time, we know that there is both a mass and a vegetable life that organizes the parts of that mass. On the one hand, the mass is a substance (a compound body). On the other hand, the vegetable life is a mode that organizes that mass. But what of the oak? I have argued that the oak is not a mode, but what else might Locke take it to be?

Martha Bolton $(2015,75-78)$ suggests one answer to this question. Bolton turns for help to an infrequently cited passage that falls near the end of 2.27 in which Locke suggests that some beings are neither substances nor modes but 'Composition[s] [...] of distinct Substances, and Different Modes' (2.27.28). In light of this passage, Bolton proposes that the oak might be neither a substance nor a mode but a composition of substances and modes: the oak, on this interpretation, is composed of both the mass (a substance) and the vegetable life (a mode). The mass and the vegetable life are two component parts that, taken together, make up the oak. This interpretation, Bolton suggests, can 
explain why it is that the oak in our example persists from $t_{1}$ to $t_{2}$ : it persists because, even though its substantial part at $\mathrm{t}_{1}$ does not survive to $\mathrm{t}_{2}$, its modal part does.

While promising, Bolton's interpretation faces at least two significant objections. First, it is worth emphasizing that Bolton must deny that the oak is a substance. As I have already emphasized, this result should come as a surprise, for Locke's view throughout the Essay seems to be that beings like oaks are paradigmatic substances. Now, Bolton actually has a response to this worry. Bolton claims that Locke often characterizes oaks (and similar beings) as 'substances' because, even though they are not strictly substances, they are in some important ways analogous to substances. Bolton thus terms such beings 'substance analogues' (2015, 65-73). Unfortunately, I do not have space to discuss the details of this intriguing suggestion. It nonetheless seems to me that it is a significant cost of Bolton's interpretation that she has to appeal to analogy in order to explain the great many texts in which Locke seems to think that oaks (and similar beings) are substances.

The second objection to Bolton's interpretation is, I think, more troublesome. According to Bolton, the difference between the oak and the mass is that the oak has a part that the mass lacks. Whereas the mass is simply a collection of particles, the oak is composed of both a collection of particles and a vegetable life that organizes this collection of particles. Bolton thus denies that the mass possesses the functional organization of the oak's vegetable life. In Bolton's words, 'Masses of particles [...] comprise several coherent particles but do not comprise their de facto arrangement' (2015, 79). This claim seems to me mistaken. The reason why there is an oak in the first place is precisely because the parts of the mass are organized in the way that they are. If the mass did not possess this functional organization, then there would be no oak. Bolton defends her interpretation by appealing to Locke's definition of a mass as a collection of atoms, 'let the parts be never so differently jumbled' (2.27.3). Locke's claim here, according to Bolton, is that a mass is a collection of particles minus the organization of those particles. The trouble with this reading is that it confuses kinds and individuals. 
Locke's claim in this passage is not that the parts of an individual mass do not possess any particular organization. Instead, his claim is that the parts of an individual mass may be organized in any way whatsoever, because there is no particular organizational structure that is essential to masses as a kind.

If the oak is neither a mode nor a 'composition' (in Bolton's sense) of substances and modes, then it looks as if the oak must be a substance after all. ${ }^{14}$ This conclusion raises a number of interpretive questions. In particular, if the oak and the mass are both substances, then we might wonder how Locke understands the synchronic relation between them. Does Locke think that the oak and the mass are two numerically distinct substances that nonetheless occupy the same spatiotemporal region ${ }^{15}$ Or, does he think that, while the oak and the mass are both substances and both occupy the same spatiotemporal region, they are not entirely 'distinct' because one of them (the mass) constitutes the other (the oak). ${ }^{16}$ Or, perhaps he thinks that there is, in some sense, only a single substance, which we may conceive of either as an oak or as a mass. ${ }^{17}$ While it is an interesting interpretive question which of these views (if any) Locke would endorse, I raise it here only to set it aside. Instead, I want to focus on the question that I raised earlier. I have argued that, on the most plausible interpretation of 2.27, it looks as if Locke thinks that oaks are substances. The general idea of oak thus seems to be the idea of a kind of substance. And yet, in 2.27.2, Locke says that we have the ideas of only three kinds of substances, the general idea of oak not among them. Moreover, one lesson that Locke draws from his discussion of the oak's diachronic identity is that the oak persists even if the substances (that is, the masses or compound bodies) to which it is successively related (in some way) do not persist. So, if Locke does think that the general idea of oak is the idea of a kind of substance, why does he write as he does in this chapter? In order to answer this question, we need to turn beyond the confines of 2.27 to Locke's theory of kinds.

\section{Locke's Abstractionist Theory of Kinds}


Locke tells a fairly straightforward abstractionist story about how we form ideas of different kinds of substances. We begin, he says, by comparing the ideas of different individual substances, noticing that they have certain ideas in common, and abstracting those commonalities to form new, general ideas of the kinds to which those individuals belong (3.3.6-7). I might abstract the general idea of man, for example, by comparing my ideas of individual men - say, Peter and Paul - and abstracting the ideas that they have in common. I might then abstract the general idea of animal by comparing the general idea of man with, for example, the general ideas of horse, salmon, and bluebird. This same process leads us to form increasingly general ideas of ever more comprehensive kinds of substances.

This abstractionist story already suggests a natural way of interpreting Locke's puzzling claim in 2.27.2 that 'We have the Ideas but of three sorts of Substances; 1. God. 2. Finite Intelligences. 3. Bodies.' The three kinds that Locke lists in this passage are, according to Locke, the three most comprehensive kinds of substances. Let's refer to these three most comprehensive kinds as 'basic' kinds. Locke's claim in 2.27.2, I suggest, is that we have the ideas of only three basic kinds of substances: God, finite intelligence, and body. ${ }^{18}$ Locke is not denying that we also have the ideas of other kinds of substances. The general ideas of man, horse, oak, and gold, for example, are indeed the ideas of so many different kinds of substances. Locke's claim is simply that they are not ideas of basic kinds of substances. Instead, they are ideas of what we can call 'non-basic' kinds of substances, less comprehensive kinds that fall under at least one of the three basic kinds. ${ }^{19}$ In fact, these examples man, horse, oak, and gold - are all examples of ideas of non-basic kinds of substances that fall under the basic kind body; that is, they are all ideas of different kinds of bodies. ${ }^{20}$

While this distinction between basic and non-basic kinds of substances helps to explain Locke's claim in 2.27.2 that 'We have the Ideas but of three sorts of Substances', we might wonder why this distinction matters to Locke. Why does he use the phrase 'sorts of Substances' in this passage 
to refer exclusively to basic kinds of substances, as opposed to non-basic kinds? In order to answer this question, we first need to observe an important consequence of Locke's abstractionist story.

Suppose that I abstract the general idea of animal from the general idea of man. Because the general idea of animal is abstracted from the general idea of man, it follows that the ideas contained in the general idea of animal are a proper subset of the ideas contained in the general idea of man; that is, every idea that is contained in the general idea of animal is also contained in the general idea of man. Likewise, if the general idea of living thing is abstracted from the general idea of animal and the general idea of body is abstracted from the general idea of living thing, then it follows that the ideas contained in the general idea of body are a proper subset of the ideas contained in the general idea of living being, which in turn are a proper subset of the ideas contained in the general ideas of animal, which in turn are a proper subset of the ideas contained in the general idea of man. The general idea of man thus contains all the ideas that are contained in the idea of any kind of substance that stands above it in the hierarchy of kinds. More generally, the idea of every non-basic kind of substance contains all the ideas that are contained in the idea of any 'higher' kind of substance.

This abstractionist theory of kinds leads Locke to his distinctive theory of definition. Locke criticizes what he takes to be the scholastic theory of definition, on which the proper definition of a species (its 'real definition') is fixed by its real essence as disclosed by the place that that species occupies in the hierarchy of kinds. On this theory, a man, for example, is defined as a rational animal because the kind man really is - in the natural order of things - a species falling under the genus animal and distinguished by the difference rational (3.6.10-11). For Locke, by contrast, the hierarchy of kinds is nothing but a more or less arbitrary division of ideas; as Locke says, 'in this whole business of Genera and Species, the Genus, or more comprehensive, is but a partial Conception of what is in the Species, and the Species, but a partial Idea of what is to be found in each individual' (3.6.32). As a result, Locke holds 
that there may be many different ways of defining a species, so long as the definiens and the definiendum signify the same simple ideas:

For, I think, that to one who desired to know what Idea the word Man stood for; if it should be said, that Man was a solid extended Substance, having Life, Sense, spontaneous Motion, and the Faculty of Reasoning, I doubt not but the meaning of the term Man, would be as well understood, and the Idea it stands for be at least as clearly made known, as when it is defined to be a rational Animal; which by the several definitions of Animal, Vivens, and Corpus, resolves it self into those enumerated Ideas. (3.3.10)

Suppose that the general idea of man contains the ideas of substance, solidity, extension, life, sense, spontaneous motion, and rationality. In this case, one way to define the general idea of man would be simply to list these constituent ideas: a man is a substance possessing solidity, extension, life, sense, spontaneous motion, and rationality. ${ }^{21}$ Locke thinks, however, that there are other ways of defining the general idea of man depending on how exactly we divide up its constituent ideas. For example, if the general idea of body contains the ideas of substance, solidity, and extension, we might define a man as a body possessing life, sense, spontaneous motion, and rationality. Or, if the general idea of living thing contains the ideas of substance, solidity, extension, and life, then we might define a man as a living thing possessing sense, spontaneous motion, and rationality. Or, if the general idea of animal contains the ideas of substance, solidity, extension, life, sense, and spontaneous motion, then we might define a man as an animal possessing rationality. Locke's point is that, since each of these definiens ultimately resolves into the same constituent ideas, none of these definitions is more accurate than any other. They are just so many different ways of dividing up the ideas contained in the general idea of man.

This theory of definition has important implications for Locke's theory of kinds. As we have just seen, Locke thinks that there are many different ways of defining the general idea of man. No matter which definition we choose, however, we must define the general idea of man in terms of both (1) the idea of another, more basic kind of substances and (2) the idea of some characteristic property or group of properties that differentiates men from other kinds of substances that fall under the same 
more basic kind. For example, if we define a man as a body possessing life, sense, spontaneous motion, and rationality, then we are defining the general idea of man as containing (1) the general idea of body, which is the idea of another kind of substance (a basic kind), and (2) the ideas of life, sense, spontaneous motion, and rationality, properties that jointly differentiate men from other kinds of bodies. Likewise, if we define a man as an animal possessing rationality, then we are defining the general idea of man as containing (1) the general idea of animal, which is the idea of another kind of substance (this time, a non-basic kind), and (2) the idea of rationality, which differentiates men from other kinds of animals.

This point generalizes to all ideas of non-basic kinds of substances. Consider, for example, the general idea of oak. Oak is a non-basic kind of substance that falls under a few more comprehensive kinds: vegetable, living thing, and body. Locke holds, therefore, that we can define an oak as a kind of vegetable, as a kind of living thing, or as a kind of body. For example, we might define the general idea of oak as containing (1) the general idea of vegetable, which is the idea of a (non-basic) kind of substance and (2) the idea of a certain kind of vegetable life (presumably, the kind of vegetable life that is unique to oaks), which differentiates oaks from other kinds of vegetables.

It is worth noting that a similar point is true of ideas of basic kinds of substances. Consider the general idea of body. Supposing that the general idea of body contains the ideas of substance, solidity, and extension, we can define a body as a substance possessing solidity and extension. Now, strictly speaking, the idea of substance is not the idea of a kind of substance; instead, it is the idea of substance itself. Therefore, we cannot define body in terms of any other kind of substance, since there are no other kinds of substance above body in the hierarchy of kinds. Nonetheless, we can define body as a substance possessing solidity and extension. This definition would have us defining the general idea of body as containing (1) the idea of substance and (2) the ideas of solidity and extension, which differentiate body from the other basic kinds of substances. 
What this discussion of Locke's theory of definition reveals is that, on Locke's view, ideas of kinds of substances have a remarkably complicated internal structure. In particular, Locke holds that the idea of any non-basic kind of substance K contains both (1) the idea of some other, more basic kind of substance and (2) the idea of a characteristic property or group of properties that differentiates $\mathrm{K}$ from other kinds of substances that fall under the same more basic kind. What kinds of ideas are (1) and (2)? (1) is obviously a substance-idea, but what about (2)? (2) is not a substance-idea; instead, (2) is the idea of a characteristic property or group of properties that does not subsist by itself, as would a substance, but instead depends upon some substance for its existence. (2) thus appears to be a mode-idea. ${ }^{22}$ If we define a man as an animal possessing rationality, then we are defining the general idea of man as containing both a substance-idea (the general idea of animal) and a mode-idea (the idea of rationality). Likewise, if we define an oak as a body possessing a vegetable life, then we are defining the general idea of oak as containing both a substance-idea (the general idea of body) and a mode-idea (the idea of vegetable life). Stated generally, therefore, Locke's view is that, for any given non-basic kind of substance K, K contains at least (1) the idea of some kind of substance that falls above $\mathrm{K}$ in the hierarchy of kinds and (2) the idea of a characteristic mode that differentiates $\mathrm{K}$ from other kinds of substances falling under the same higher kind. In this sense, we might say that ideas of non-basic kinds of substances are composed of both substance-ideas and mode-ideas. To this extent, there is a kernel of truth in Bolton's suggestion that an oak, for example, is a composite being that is composed of both substances and modes. Indeed, this may be what Locke has in mind in that passage that Bolton cites from 2.27.28 in which Locke says that some beings are 'Composition[s] [...] of distinct Substances, and Different Modes'. Importantly, however, this composition arises not because Locke endorses the metaphysical thesis that some substances have both a substantial part and a modal part but rather because of his idiosyncratic theory of definition. 
One peculiarity of Locke's view is worth emphasizing. While I have argued that, for Locke, ideas of non-basic kinds of substances are composed of both substance-ideas and mode-ideas, there is a certain indeterminacy regarding exactly which substance-ideas and mode-ideas they contain. As we have seen, Locke thinks that there may be many different yet equally correct ways of defining the idea of any given kind of substance, depending on how exactly we divide up its constituent ideas. We can equally well define a man, for example, as a kind of body or as a kind of animal. If we divide up its constituent ideas in one way, it will turn out that it contains the general idea of body along with the idea of a characteristic mode that differentiates men from other kinds of bodies. If we divide up its constituent ideas in another way, it will turn out that it contains the general idea of animal along with the idea of a characteristic mode that differentiates men from other kinds of animals. There is no deep fact of the matter about which of these ideas it actually contains. It all depends on how we choose to divide up its constituent ideas.

It might be objected that there are principled reasons for doubting that substance-ideas can contain mode-ideas. ${ }^{23}$ When Locke first discusses substance-ideas, he says that 'Ideas of Substances are such combinations of simple Ideas, as are taken to represent distinct particular things subsisting by themselves' (2.12.6). On a straightforward reading, Locke's claim here seems to be that substanceideas are composed exclusively of simple ideas and, therefore, do not contain other complex ideas. Since mode-ideas are complex ideas, it would follow that substance-ideas cannot contain mode-ideas.

I have three responses to this objection. First, on my interpretation, substance-ideas are indeed composed of simple ideas. I have argued that substance-ideas can contain other complex ideas, including mode-ideas. Since these other complex ideas are ultimately composed of simple ideas, it follows that the substance-ideas that they comprise likewise are ultimately composed of simple ideas. Therefore, my interpretation is consistent with Locke's claim that substance-ideas are 'combinations 
of simple Ideas' because, while substance-ideas do contain complex ideas, those complex ideas themselves are ultimately composed of simple ideas.

Second, if substance-ideas could not contain other complex ideas, it would follow not only that substance-ideas cannot contain mode-ideas but also that substance-ideas cannot contain other substance-ideas. Locke clearly rejects this claim, however, because he holds that some substance-ideas are abstracted from other substance-ideas. If the general idea of animal is abstracted from the general idea of man, for example, then it seems to follow that the general idea of man (a substance-idea) contains the general idea of animal (another substance-idea).

Third, there are passages in which Locke explicitly claims that substance-ideas contain modeideas, specifically, complex ideas of powers. He writes that 'Powers make a great part of our complex Ideas of Substances' (2.23.8), as for example 'the power of drawing Iron, is one of the Ideas of the Complex one of that substance we call a Load-stone, and a Power to be so drawn is a part of the Complex one we call Iron' (2.23.7). Locke acknowledges explicitly that these ideas of powers are complex ideas:

For he has the perfectest Idea of any of the particular sorts of Substance, who has gathered, and put together, most of those simple Ideas, which do exist in it, among which are to be reckoned its active Powers, and passive Capacities; which though not simple Ideas, yet, in this respect, for brevity's sake, may conveniently enough be reckoned amongst them. (2.23.7)

Moreover, Locke indicates elsewhere that complex ideas of powers, such as those contained in ideas of kinds of substances, are mode-ideas. In the chapter entitled 'Of Mixed Modes', Locke says that the simple idea of power is one of 'those, which have been most modified; and out of whose Modifications have been made most complex Modes, with names to them', and he goes on to give the example of 'Boldness', which is 'the Power to speak or do what we intend, before others, without fear or disorder' (2.22.10). In other words, Locke's view is that the complex idea of the power of boldness is a modeidea that contains the simple idea of power as one of its constituents. ${ }^{24}$ In the same way, the complex idea of the power to be drawn by a load-stone, which Locke takes to be part of the general idea of 
iron, is also a mode-idea. So, Locke not only accepts that substance-ideas can contain mode-ideas but actually claims that many substance-ideas do, in fact, contain mode-ideas.

Even if Locke himself accepts that substance-ideas can contain mode-ideas, we might think that there is something philosophically puzzling about this claim. Earlier, I said that the chief difference between substance-ideas and mode-ideas is that substance-ideas are ideas of self-subsistent beings while mode-ideas are ideas of dependent beings. There are other differences, however. ${ }^{25}$ Locke says that mode-ideas 'are not only made by the Mind, but made very arbitrarily, made without Patterns, or reference to any real Existence' (3.5.3). In this respect, mode-ideas differ from substance-ideas, 'which carry with them the Supposition of some real Being, from which they are taken, and to which they are conformable' (3.5.3). As a result, whereas substance-ideas are 'intended to be Representations of Substances, as they really are' (2.30.5), mode-ideas (or, more specifically, their names) are intended 'to denominate all Things, that should happen to agree to' those mode-ideas (3.6.46). Given these differences, it might seem as if substance-ideas cannot contain mode-ideas. After all, if substance-ideas are intended to represent things as they really are, then it seems as if they cannot contain mode-ideas, since mode-ideas are not intended to represent things as they really are.

I think that Locke's theory of definition offers a response to this challenge. Consider the general idea of man. The general idea of man contains a number of ideas, including the ideas of substance, solidity, extension, life, sense, spontaneous motion, and rationality. It contains these ideas because all of the men that we have actually encountered have had these features in common, and the general idea of man is a substance-idea that is intended to represent things as they really are. As we have seen, however, Locke thinks that there are many different ways of dividing up these constituent ideas. For example, we can just as well define a man as a body possessing life, sense, spontaneous motion, and rationality, or as a living thing possessing sense, spontaneous motion, and rationality. So, suppose that we combine the ideas of life, sense, spontaneous motion, and rationality to form a new 
idea, call it the idea of 'human life'. We can now say that a man is a body possessing human life. In this case, while it is true that the idea of man contains the ideas that it does (substance, solidity, extension, life, sense, spontaneous motion, and rationality) only because it is intended to represent things as they really are, there is nonetheless something arbitrary about the way in which we divide up those ideas when we define a man as a body possessing human life. After all, we could have defined a man not as a body possessing human life but as a living thing possessing some other characteristic property or properties. As a result, while the general idea of man is intended to represent things as they really are, the idea of human life is made, as Locke says, 'very arbitrarily, made without Patterns, or reference to any real Existence'. In other words, the idea of human life is a mode-idea; indeed, it is the idea of the characteristic mode that differentiates men from other bodies. Of course, since we form the idea of human life only because we have actually observed humans, the idea of human life is in this sense not formed arbitrarily. Locke says, however, that we often form mode-ideas 'By Experience and Observation of things themselves', as when 'seeing two Men wrestle, or fence, we get the Idea of wrestling or fencing' (2.22.9). The point is simply that we did not have to combine the ideas contained in the general idea of man in just the way that we did. Whereas we would have been making a mistake if we had included, say, the idea of immortality in the general idea of man, we would not have been making a mistake had we divided up the ideas contained in the general idea of man in some other way.

I have been arguing that, for Locke, ideas of non-basic kinds of substances are composed of both substance-ideas and mode-ideas. We can now return to the question that I posed earlier in this section: why does Locke distinguish in 2.27 between basic and non-basic kinds of substances? Why does he claim in 2.27.2 that we have the ideas of only three (basic) kinds of substances, given that he clearly also thinks that we have the ideas of many, many more (non-basic) kinds of substances?

The answer, I think, is that Locke takes there to be a significant difference between the diachronic identity conditions for basic and non-basic kinds of substances. We have already 
encountered Locke's account of the diachronic identity conditions for basic kinds of substances, which consist (very roughly) in the strict spatiotemporal continuity of constituent parts; for example, a mass at one time is identical to a mass at another time just in case every atom in the earlier mass is spatiotemporally continuous with some atom in the later mass and vice versa. By contrast, Locke argues that the diachronic identity conditions for non-basic kinds of substances are different from the diachronic identity conditions of the basic kinds under which they fall. An oak can continue to exist, for example, even if the mass (a compound body) in which its vegetable life is momentarily realized ceases to exist. Instead, Locke holds that the diachronic identity conditions for non-basic kinds of substances such as oaks are determined exclusively by their characteristic modes. The oak continues to exist, for example, just in cases its vegetable life continues to exist, regardless of whether that vegetable life is realized in numerically the same mass. The diachronic identity of the oak (a non-basic kind of substance) thus depends not on the diachronic identity of the mass (a basic kind of substance) but on the diachronic identity of its vegetable life, which is the characteristic mode that distinguishes oaks from other kinds of bodies.

The distinction between basic and non-basic kinds of substances is thus an important component of Locke's theory of identity. For the purposes of 2.27, therefore, Locke distinguishes two broad classes of substances. On the one hand, the diachronic identity of basic kinds of substances consists in the strict spatiotemporal continuity of their constituent parts. On the other hand, the diachronic identity of non-basic kinds of substances depends exclusively on the continued existence of the characteristic modes that distinguish each non-basic kind of substance from every other nonbasic kind of substance falling under the same basic kind.

We might wonder how broadly Locke means to apply this strategy. Locke focuses his attention chiefly on organisms: 'In the state of living Creatures, their Identity depends not on a Mass of the same Particles; but on something else' (2.27.3). Later, he suggests taking a similar approach to some 
artifacts: 'Something we have like this in Machines, and may serve to illustrate it. For Example, what is a Watch? 'Tis plain, 'tis nothing but a fit Organization, or Construction of Parts, to a certain end' (2.27.5). In principle, however, it seems open to Locke to apply much the same strategy to all nonbasic kinds of substances whatsoever. It follows from Locke's theory of definition that the idea of any non-basic kind of substance can be defined in terms of some basic kind of substance. Schematically, a non-basic kind of substance is a basic kind of substance differentiated by a characteristic mode. So, on this strategy, for any non-basic kind of substance, the diachronic identity of that non-basic kind of substance depends on the diachronic identity of its characteristic mode. We can thus apply this strategy to cases that Locke does not consider explicitly. For example, what is it for a loadstone at one time to be identical to a loadstone at another time? Well, a loadstone is a body possessing a certain group of characteristic properties - 'Hardness, Friability, and Power to draw Iron' (2.23.3). We can combine the ideas of these qualities to form the idea of a characteristic mode M that differentiates loadstones from other kinds of bodies. Locke's view, then, is that the loadstone continues to exist so long as M continues to exist. This is why the loadstone can continue to exist even if I chip off one corner. In this case, the compound body in which $\mathrm{M}$ was formerly realized ceases to exist, but the loadstone nonetheless continues to exist in virtue of the fact that its characteristic mode continues to exist in a new, slightly smaller body.

\section{Persons}

Much more could be said about Locke's theory of identity. Instead of pursuing these issues further, however, I want to return to persons and to the debate between the substance interpretation and the mode interpretation. Is the general idea of person the idea of a kind of substance or is it instead the idea of a kind of mode? Prima facie, Locke's claim in 2.27 that we have the ideas of only three kinds of substances (the general idea of person not among them) and that sameness of substance is neither necessary nor sufficient for sameness of person might seem to weigh against the substance 
interpretation. Our discussion so far belies this appearance, however. Even if the general idea of person is not the idea of a basic kind of substance, it might nonetheless be the idea of a non-basic kind of substance, just as the general idea of oak is the idea of a non-basic kind of substance. In this section, I am going to argue that a close reading of Locke's discussion of persons confirms this hypothesis.

Locke begins his discussion with the following definition:

This being premised to find wherein personal Identity consists, we must consider what Person stands for; which, I think, is a thinking intelligent Being, that has reason and reflection, and can consider it self as it self, the same thinking thing in different times and places [...]. (2.27.9)

A person, Locke says, is a 'thinking intelligent Being' that possesses certain cognitive abilities, such as 'reason and reflection'. We can begin with the first part of this definition. What is a 'thinking intelligent Being'? One natural proposal is that a 'thinking intelligent Being' is a finite intelligence, one of the three basic kinds of substances from 2.27.2. In order to evaluate this proposal, however, we need to know more about finite intelligences. Locke does not use the phrase 'finite intelligences' anywhere else in the Essay. Later in 2.27.2, however, Locke refers to finite intelligences as 'Finite Spirits'. And, elsewhere in the Essay, Locke has quite a lot to say about finite spirits. In 2.23.15-32, Locke distinguishes the idea of material substance or body from the idea of immaterial substance or spirit. ${ }^{26,27}$ Whereas the general idea of body is the idea of a substance possessing extension and solidity, the general idea of spirit is the idea of a substance possessing the powers of thought and will. ${ }^{28}$ As a result, just as different kinds of bodies (oaks, animals, and so on) are different kinds of substances that all possess extension and solidity, so too different kinds of spirits - or, in the language of 2.27.2, different kinds of finite intelligences - are different kinds of substances that possess the powers of thought and will. ${ }^{29}$ So, when Locke says in 2.27.9 that a person is a 'thinking intelligent Being', it is natural to read him as emphasizing that a person is not a kind of body, that is, a substance that possesses extension 
and solidity; instead, a person is a kind of spirit or finite intelligence, that is, a substance that possesses the powers of thought and will.

Proponents of the mode interpretation may wish to object to this reading. Locke makes it clear elsewhere that substances and modes are two kinds of 'beings'. Therefore, Locke could be using the phrase 'thinking intelligent Being' to designate a mode rather than a substance. Perhaps Locke's point is simply that the general idea of person contains the ideas of thinking, intelligence, and beingall of which is consistent with the general idea of person being the idea of a kind of mode. This interpretation does not seem very plausible, however. Since the idea of being is a simple idea that may be abstracted out of absolutely any idea whatsoever (3.3.9), Locke thinks that all ideas contain the idea of being. It would be odd if he were doing nothing more than emphasizing this mundane fact. Instead, I think that Locke is making the more significant claim that the general idea of person is the idea of a being that possesses thought and intelligence. This point is significant because thought and intelligence are both powers, and Locke argues elsewhere that only substances possess powers, writing for example that 'Powers belong only to Agents, and are Attributes only of Substances' (2.21.16). ${ }^{30}$ Locke's view thus seems to be that persons are beings - specifically, substances - that possess the powers of thought and intelligence. In other words, persons are finite intelligences. This argument is unlikely to persuade committed proponents of the mode interpretation. Antonia LoLordo (2012, 99-101), for example, has attempted to defend the mode interpretation by arguing that modes are able to inherit powers from the substances upon which they depend. LoLordo's arguments lies well beyond the scope of this paper. Nonetheless, I think that it is at least clear that the burden of proof is on proponents of the mode interpretation to explain why we should not read Locke as using the phrase 'thinking intelligent Being' to claim that persons are finite intelligences.

We can turn now to the second part of the definition. A person, for Locke, is not just any old finite intelligence. Just as there are many different kinds of bodies, so too might there be many 
different kinds of finite intelligences. For example, since Locke thinks that there are at least some animals that are capable of thought, he likely holds that such animals are finite intelligences but not persons. ${ }^{31}$ Accordingly, when Locke offers his definition of the general idea of person in 2.27.9, he says that a person is a finite intelligence 'that has reason and reflection, and can consider it self as it self, the same thinking thing in different times and places' (2.27.9). In other words, a person is a finite intelligence that possesses certain cognitive abilities. While there may be some non-person animals that are also finite intelligences, such animals are not persons because they lack the cognitive abilities that are characteristic of persons. It is the possession of these cognitive abilities, therefore, that differentiates persons from other kinds of finite intelligences.

So far, Locke's view seems to be that a person is a finite intelligence that possesses certain cognitive abilities. I will complicate this neat picture momentarily. Before doing so, however, I want to draw our attention to what Locke is doing in 2.27.9. In this passage, Locke is defining the general idea of person in terms of (1) the idea of finite intelligence, which is the idea of a basic kind of substance, and (2) the idea of a characteristic mode that differentiates persons from other kinds of finite intelligences. In other words, Locke is treating the idea of person as the idea of a non-basic kind of substance, a finite intelligence differentiated by a characteristic mode. Just as an oak is a body that possesses vegetable life, so too a person is a finite intelligence that possesses certain cognitive abilities. Locke's definition of the general idea of person in 2.27.9 thus provides strong confirmation for the hypothesis that Locke takes the general idea of person to be the idea of a non-basic kind of substance.

Immediately after offering this neat definition, however, Locke complicates his position by shifting his attention away from the cognitive abilities that are characteristic of persons and towards 'that consciousness, which is inseparable from thinking, and as it seems to me essential to it':

When we see, hear, smell, taste, feel, meditate, or will any thing, we know that we do so. Thus it is always as to our present Sensations and Perceptions: And by this every one is to himself, that which he calls self [...]. For since consciousness always accompanies thinking, and 'tis that, that makes every one to be, what he calls self; and thereby distinguishes himself from all other 
thinking things, in this alone consists personal Identity, i.e. the sameness of a rational Being [...]. $(2.27 .9)$

In the next section, Locke goes on to compare the consciousness of a person with the life of a plant or animal:

The Question being what makes the same Person, and not whether it be the same Identical Substance, which always thinks in the same Person, which in this case matters not at all. Different Substances, by the same consciousness (where they do partake in it) being united into one Person; as well as different Bodies, by the same Life are united into one Animal, whose Identity is preserved, in that change of Substances, by the unity of one continued Life. For it being the same consciousness that makes a Man be himself to himself, personal Identity depends on that only, whether it be annexed only to one individual Substance, or can be continued in a succession of several Substances. (2.27.10)

How ought we to understand this analogy between consciousness and life? An example may help to illustrate the suggestion. Suppose that I find myself caught up in a sword fight. My opponent swings her blade and catches my left hand. At the moment of contact, I see the blade making contact with my left hand, I feel a sharp, cutting pain, and I will to use the sword in my right hand to stave off the attack. In this example, I am the subject of several mental states - seeing, feeling, and willing. Locke's view, it seems, is that each of these mental states belongs to my person because each is conscious and, therefore, is unified by consciousness into my person. In this sense, consciousness is constitutive of persons in much the same way as vegetable life is constitutive of oaks. Just as the material parts of an oak are unified into a single oak both at a time and over time by the vegetable life that organizes those parts in such a way as 'to frame the Wood, Bark, and Leaves, etc. of an Oak' (2.27.4), so too are the disparate mental states of seeing, feeling, and willing unified into a single person by the consciousness that holds them all together so as to form a unified whole.

One complicating factor here is that persons can have bodily as well as mental constituents. A person, Locke says, may be 'vitally united' to a body (2.27.11). While Locke himself is agnostic about the exact nature of this vital union, one result of it is that a person is able to be conscious of the material parts of the body to which it is vitally united. Consequently, just as consciousness unifies my 
mental states into my person, so too (and for the same reason) does consciousness unify (some of) the parts of my body into my person. ${ }^{32}$ As Locke says, 'the Limbs of his Body is to every one a part of bimself (2.27.11). In fact, Locke seems to think not just that the parts of my body can belong to my person but also that some of the motions of my body can belong to my person. He often speaks of consciousness as uniting actions into persons. Some of these actions are obviously mental actions, acts of willing in particular. But, when my acts of willing cause motions in my body, the resulting motions seem likewise to be actions that I perform. Indeed, this claim seems to follow from Locke's own principles. When I move my hand, I am conscious both of willing to move my hand (a mental action) and also of moving my hand (a bodily action). Consciousness ought, therefore, to unify both of these actions into my person. Indeed, Locke himself sometimes suggests as much, as when he says that his present act of writing belongs to his person in virtue of his present consciousness of his own act of writing (2.27.16).

Locke thus holds that consciousness is constitutive of persons in much the same way as vegetable life is constitutive of oaks. In order to understand this claim, however, we need to recognize an ambiguity in Locke's use of the word 'consciousness'. ${ }^{33}$ Locke introduces the idea of consciousness into his discussion of personhood by noting that 'consciousness always accompanies thinking, and 'tis that, that makes every one to be, what he calls self (2.27.9). Here, 'consciousness' seems to refer to something like a property of each of the mental and bodily states that belong to one's person. Likewise, the idea of 'consciousness' seems to be a simple idea of reflection, obtained through reflection upon our conscious mental and bodily states. To say that something is 'conscious' in this sense is just to say that I am aware of it in a certain way and, therefore, that it is a part of my person. Locke thus holds that consciousness 'makes every one to be, what he calls self because consciousness is that property that unifies a person's mental and bodily constituents into a single whole. 
Elsewhere in the chapter, however, Locke uses the word 'consciousness' rather differently. Towards the end of the chapter, for example, he imagines two persons, 'the Day and the Night-man', operating by turns in one and the same body (2.27.23). Strikingly, Locke describes this as a case of 'two distinct incommunicable consciousnesses acting the same Body', arguing that the Day-man and the Night-man would be two distinct persons in virtue of the fact that each possesses his own consciousness. While the meaning of the word 'consciousness' in this passage is far from clear, what does seem relatively clear is that 'consciousness' does not here refer to a property of mental and bodily states. Instead, 'consciousness' seems to refer to something like the unified whole that is generated out of a collection of conscious mental and bodily states. The Day-man and the Night-man have two distinct consciousnesses, it seems, in the sense that there are not one but two unified wholes, which seem importantly distinct from one another. Understood in this way, the idea of 'consciousness' is not a simple idea of reflection but a mode-idea, specifically, the idea of a unified collection of mental and bodily states. Locke's use of the word 'consciousness' is thus ambiguous between, on the one hand, the unifying property of one's mental and bodily states and, on the other hand, the unified whole that is generated out of those states.

Locke's discussion of consciousness complicates his definition of the general idea of person. A person, for Locke, is not merely a finite intelligence that possesses certain cognitive abilities. Persons also possess a distinctive kind of unity. A person is a finite intelligence, the mental and bodily constituents of which are unified by consciousness (understood as a unifying property) into a single consciousness (understood as a unified whole). Locke's discussion thus suggests that there are actually two properties that are individually necessary and jointly sufficient for a finite intelligence to be a person: a finite intelligence is a person if and only if that finite intelligence possesses (1) certain cognitive abilities and (2) a consciousness. 
We might wonder how Locke understands the relation between (1) and (2). Perhaps Locke thinks that the one entails the other. If a finite intelligence possesses the cognitive abilities that are characteristic of persons, does it necessarily follow that it must also possess a consciousness? Or, if a finite intelligence possesses a consciousness, does it necessarily follow that it also possesses the cognitive abilities that are characteristic of persons? Locke's position on this matter is not clear. What is clear, however, is that Locke often treats the possession of a consciousness as not only necessary but also sufficient for personhood. In one passage, for example, he imagines someone losing her little finger and writes that, if that person's 'consciousness [should] go along with the little Finger, and leave the rest of the Body, 'tis evident the little Finger would be the Person, the same Person' (2.27.17). Perhaps Locke thinks that, if my consciousness were housed in my finger, then my finger would necessarily possess the cognitive abilities that are characteristic of persons. Or, perhaps Locke is simply being careless in this passage; perhaps he thinks that, strictly speaking, in order for my finger to become a person, it would not only have to house my consciousness but would additionally have to possess those cognitive abilities that are characteristic of persons. Either way, the important point is that Locke seems happy to treat the possession of a consciousness as both necessary and sufficient for personhood, whatever the relationship might be between the possession of a consciousness and the possession of those cognitive abilities that are characteristic of persons.

Supposing that the possession of consciousness is both necessary and sufficient for personhood, we can offer a new definition of the general idea of person on Locke's behalf: a person is a finite intelligence that possesses a consciousness. Importantly, while this definition is different from the one that I earlier extracted from 2.27.9 (on which a person is a finite intelligence that possesses certain cognitive abilities), both definitions are structurally the same. A person, for Locke, is a non-basic kind of substance falling under the basic kind finite intelligence and differentiated by a characteristic mode, either the possession of certain cognitive abilities or the possession of a 
consciousness. The general idea of person, therefore, is the idea of a non-basic kind of substance, containing both the idea of a basic kind of substance and the idea of a characteristic mode.

This definition of the general idea of person gives rise to Locke's account of personal identity. Earlier, I argued that, for Locke, the diachronic identity of a non-basic kind of substance depends on the continued existence of the characteristic mode that differentiates that non-basic kind of substance from other non-basic kinds of substances falling under the same basic kind. An oak continues to exists, for example, just in cases its vegetable life continues to exist, regardless of whether that vegetable life is realized in numerically the same compound body. Locke's account of personal identity has the same structure: 'For since consciousness always accompanies thinking, and 'tis that, that makes every one to be, what he calls self; and thereby distinguishes himself from all other thinking things, in this alone consists personal Identity, i.e. the sameness of a rational Being' (2.27.9). For Locke, a person is a finite intelligence possessing a consciousness. Accordingly, Locke argues that a person continues to exist just in case its consciousness continues to exist, regardless of whether that consciousness is realized in numerically the same finite intelligence. The continued existence of a person thus depends entirely on the continued existence of that person's consciousness, which is the characteristic mode that distinguishes persons from other kinds of finite intelligences. ${ }^{34}$

Of course, much more could be said about Locke's account of personal identity. In particular, we might wonder what exactly it means for a person's consciousness to continue to exist. Locke says surprisingly little about this issue, although he does emphasize the analogy between consciousness and life: 'Different Substances, by the same consciousness (where they do partake in it) being united into one Person; as well as different Bodies, by the same Life are united into one Animal, whose Identity is preserved, in that change of Substances, by the unity of one continued Life' (2.27.10). The important point to recognize for our purposes is simply that, on Locke's view, the continued existence of a person or oak depends entirely on the continued existence of its consciousness (in the case of persons) 
or vegetable life (in the case of oaks). More generally, the diachronic identity conditions for non-basic kinds of substances like persons and oaks are determined entirely by the diachronic identity conditions of their characteristic modes.

On the whole, therefore, Locke's discussion of persons in 2.27 provides strong evidence for thinking that he takes the general idea of person to be the idea of a non-basic kind of substance, containing both a substance-idea (the general idea of finite intelligence) and the idea of a characteristic mode (a consciousness) that distinguishes persons from other kinds of finite intelligences. It is this account of persons, moreover, that gives rises to Locke's famous account of personal identity, on which sameness of consciousness is both necessary and sufficient for sameness of person.

\section{Conclusion}

I have had two goals in this paper. My narrower goal has been to argue for the substance interpretation and against the mode interpretation. My broader goal, however, has been to argue for a more sophisticated understanding of Locke's account of ideas of kinds of substances. These two goals are closely connected. I think that the debate between proponents of the substance interpretation and proponents of the mode interpretation has been muddied by certain misconceptions about Locke's theory of kinds and, in particular, by too rigid an understanding of the distinction between substance-ideas and mode-ideas. I have argued that, on Locke's view, ideas of non-basic kinds of substances are actually composed of both substance-ideas and mode-ideas. As a result, while I side with proponents of the substance interpretation in holding that the general idea of person is the idea of a kind of substance, I think that proponents of the mode interpretation are correct to insist that mode-ideas play a significant role in Locke's theory. In fact, I have suggested that Locke intentionally gives mode-ideas a particularly prominent role in 2.27 because he think that the persistence conditions for non-basic kinds of substances are dictated by their characteristic modes. The problem with the 
mode interpretation is simply that, while the general idea of person does contain a mode-idea, it is not itself a mode-idea but a substance-idea, specifically, the idea of a non-basic kind of substance. ${ }^{35}$

Department of Philosophy

Yale University

\section{Bibliography}

Bolton, M. B. (2015). 'Locke's Account of Substance in Light of His General Theory of Identity,' in P. Lodge and T. Stoneham (eds.) Locke and Leibniz on Substance. New York and London: Routledge, pp. 63-88.

Chappell, V. (1990). 'Locke on the Ontology of Matter, Living Things and Persons,' Philosophical Studies 60(1/2), pp. 19-32.

Connolly, P. J. (2017). 'The Idea of Power and Locke's Taxonomy of Ideas,' Australasian Journal of Philosophy 95(1), pp. 1-16.

Gordon-Roth, J. (2015). 'Locke on the Ontology of Persons,' The Southern Journal of Philosophy 53(1), pp. $97-123$.

Locke, J. (1975). An Essay concerning Human Understanding, P. H. Nidditch, ed. Oxford: Clarendon Press. LoLordo, A. (2013). 'Reply to Rickless,' Locke Studies 13, pp. 53-62.

LoLordo, A. (2012). Locke's Moral Man. Oxford: Oxford University Press.

LoLordo, A. (2010). 'Person, Substance, Mode and 'the moral Man' in Locke's Philosophy,' Canadian Journal of Philosophy 40(4), pp. 643-667.

McCann, E. (2008). 'Identity, Essentialism, and the Substance of Body in Locke,' in P. Hoffman, D. Owen, and G. Yaffe (eds.) Contemporary Perspectives on Early Modern Philosophy: Essays in Honor of Vere Chappell. Peterborough, Ontario: Broadview Press, pp. 173-190. 
Rickless, S. C. (2013). 'Locke on Active Power, Freedom, and Moral Agency,' Locke Studies 13, pp. 3354.

Rickless, S. C. (2015). 'Are Locke’s Persons Modes or Substances?’ in P. Lodge and T. Stoneham (eds.) Locke and Leibniz, on Substance. New York and London: Routledge, pp. 110-127.

Simendić, M. (2015). 'Locke's Person is a Relation,' Locke Studies 15, pp. 79-97.

Stuart, M. (2013). Locke’s Metaphysics. Oxford: Oxford University Press.

Thiel, U. (2011). The Early Modern Subject: Self-Consciousness and Personal Identity from Descartes to Hume. Oxford: Oxford University Press.

Uzgalis, W. L. (1990). 'Relative Identity and Locke's Principle of Individuation,' History of Philosophy Quarterly 7(3), pp. 283-297.

Weinberg, S. (2016). Consciousness in Locke. Oxford: Oxford University Press. 
${ }^{1}$ All in-text citations refer to the Nidditch edition of Locke's Essay by book, chapter, and section.

${ }^{2}$ The literature on this debate is extensive. Two recent defenses of the substance interpretation are Gordon-Roth (2015) and Rickless (2015). Two recent defenses of the mode interpretation are LoLordo (2012; 2010) and Thiel (2011, 97-150). See also Simendić (2015) for the claim that the idea of a person is a relation-idea.

${ }^{3}$ While all mode-ideas are ideas of dependences, not all ideas of dependences are mode-ideas. The idea of red, for example, is the idea of a quality that depends on at least one substance for its existence, but the idea of red is a simple idea rather than a mode-idea.

${ }^{4}$ For example, Locke's discussion in 2.31 of the extent to which different ideas are 'adequate' or 'inadequate' representations of their objects clearly foreshadows the themes of Book 4.

5 This distinction is closely related to but also somewhat different from Aristotle's distinction between primary and secondary substances. The idea of an individual person is the idea that we might form of that person through sensation, as when I actually see Socrates strolling through the agora. One shortcoming of Locke's theory is that he says almost nothing about our general ideas of individuals. He seems to assume that ideas of individuals are never general. This assumption is likely mistaken. When I say, 'Socrates was the teacher of Plato', the word 'Socrates' signifies my idea of Socrates. This idea of Socrates is the idea of an individual person, yet it is also arguably a general idea because it does not represent Socrates at a particular time or place (even if it may contain some spatiotemporal information, such as that Socrates was born in such-and-such a year and lived in Athens).

${ }^{6}$ See e.g. Thiel $(2011,107-109)$ for this kind of argument.

${ }^{7}$ Cf. Uzgalis $(1990,286-290)$, who accepts this implication.

${ }^{8}$ We might be tempted to read Locke as speaking loosely in these passages from 2.23 and 3.6. Perhaps Locke's considered view is the one that he expresses in 2.27.2, that we have the ideas of only three kinds of substances. The trouble with this suggestion is that 2.23 and 3.6 contain Locke's most detailed discussion of ideas of substances. By contrast, 2.27 discusses ideas of substances only insofar as they are relevant to Locke's theory of identity. So, if anything, we ought to read Locke as speaking loosely in 2.27 rather than in 2.23 and 3.6.

${ }^{9}$ Locke seems to think that what he says about simple bodies will hold mutatis mutandis for finite intelligences and God.

${ }^{10}$ See e.g. McCann $(2008,181)$ and Stuart $(2013,304)$.

${ }^{11}$ Uzgalis (1990, 286-290) makes something like this suggestion.

${ }^{12}$ In claiming that a collection of particles 'forms' an oak, I do not mean to imply that the collection of particles that forms an oak therefore itself is an oak. Locke's views concerning the synchronic relation between the oak and the mass in which its vegetable life is realized is a matter of considerable interpretive debate. While I will outline a few interpretative possibilities towards the end of this section, I do not wish to take a stand on the matter in this paper.

${ }^{13}$ It is unclear whether Locke understands the identity between $V_{1}$ and $V_{2}$ as token-identity or type-identity. That is, it is unclear whether Locke thinks that numerically the same token mode can 'pass' from one mass to its successor, or whether he instead thinks that the two successive masses merely possess the same type of functional organization.

${ }^{14}$ The same reasons that weigh against the oak being a mode also weigh against the oak being a relation.

15 This view is known as the 'coincidence' interpretation. See Chappell (1990) for the classic exposition.

16 McCann $(2008,188-189)$ tentatively suggests such an interpretation.

${ }^{17}$ This view is suggested by the 'relative identity' interpretation. See Stuart $(2013,297-338)$ for a recent defense.

${ }_{18}$ Of course, we might discover a substance that is neither God, nor a finite intelligence, nor a body. Locke is not making the dogmatic metaphysical claim that there are only three basic kinds of substances and that all substances must fall under at least one of these three. Instead, he is merely cataloging our ideas and making the contingent, empirical claim that, as a matter of fact, we only have the ideas of three basic kinds of substances.

${ }^{19}$ It follows from the distinction between basic and non-basic kinds of substances that every non-basic kind must fall under at least one basic kind. If there were some non-basic kind $\mathrm{K}$ that did not fall under at least one of the three basic kinds that Locke lists (God, finite intelligence, and body), then it would follow either that $\mathrm{K}$ itself is actually a basic kind or that $\mathrm{K}$ is a non-basic kind that falls under some other basic kind. Note also that, while every non-basic kind must fall under at least one basic kind, this distinction leaves open the possibility that a single non-basic kind might fall under more than one basic kind.

20 The distinction between basic and non-basic kinds of substances differs from the distinction between simple and compound substances. Whereas the former distinction concerns kinds of substances, the latter concerns individual substances falling under some kind. For example, whereas body is basic kind of substance, individual bodies falling under that kind may be either simple or compound.

${ }^{21}$ Since some of these constituent ideas are complex ideas, we might give a more detailed definition of the general idea of man by decomposing these complex ideas into simple ideas. 
${ }^{22}$ In principle, (2) could be either a mode-idea or a relation-idea or a complex idea composed of both mode-ideas and relation-ideas. All that matters for my purposes is that (2) is a complex idea that is not a substance-idea. For simplicity, I will assume in what follows that (2) is a mode-idea.

${ }^{23}$ I am grateful to an anonymous referee for pressing me on this point.

${ }^{24}$ See Connolly $(2017,7-11)$ for more on the distinction between, on the one hand, the simple idea of power and, on the other hand, the complex ideas of particular powers that Locke takes to form part of our ideas of kinds of substances.

${ }^{25}$ See LoLordo (2010) for a helpful survey of these differences. LoLordo argues that this survey supports the mode interpretation, but cf. Rickless (2015) for a defense of the substance interpretation in response to LoLordo's arguments.

${ }^{26}$ Locke notes in 2.23.19 that he is concerned with finite rather than infinite spirits in these passages.

${ }^{27}$ After distinguishing the ideas of body and spirit in 2.23.15-32, Locke goes on in 2.23.33-36 to explain how we arrive at the idea of God. Locke's list of the three basic kinds of substances in 2.27 .2 is thus drawn from his earlier discussion in 2.23 .

${ }^{28}$ Locke actually gives a few, importantly different definitions of body and spirit, but these differences need not concern us here.

${ }^{29}$ We ought to be careful not to equate Locke's finite intelligences with Cartesian souls. Whereas the general idea of body contains the ideas of extension and solidity, the general idea of finite intelligence does not contain these ideas and, in this sense, is not the idea of a material (that is, an extended and solid) substance. Locke nonetheless thinks that it is at least conceptually possible that a single substance might be both a body and a finite intelligence. Such a substance would possess both the properties characteristic of bodies (extension and solidity) and the properties characteristic of finite intelligences (the powers of thought and will).

${ }^{30}$ For further discussion of this argument, see Gordon-Roth (2015, 101-105). See also Chappell $(1990,28)$ and Rickless (2015, 124-125).

31 One wrinkle is that Locke sometimes says that, in order for a being to qualify as a finite intelligence, that being must possess not only the power of thought but also the power of will, and it is unclear whether Locke thinks that animals possess the power of will. Rickless $(2013,45-47)$ argues that Locke denies the power of will to animals, but cf. LoLordo's (2013, 55-56) response to Rickless.

32 While persons can have bodily constituents, they need not. An angel, for example, might plausibly be a person that is not vitally united to a body and that therefore does not have any bodily constituents.

${ }^{33}$ Weinberg $(2016,145-182)$ is particularly sensitive to this ambiguity, although I disagree with some of the metaphysical implications that she draws from it.

${ }^{34}$ I thus agree with Gordon-Roth's $(2015,118)$ suggestion that, when Locke says that sameness of substance is neither necessary nor sufficient for sameness of person, his claim is simply that "the body, man, and soul any person is related to need not be the same for her to persist, and even if they persist, she may fail to persist."

${ }^{35}$ I am grateful to Donald Ainslie, Justin Broackes, Steve Darwall, Michael Della Rocca, Jeff McDonough, Lex Newman, Marleen Rozemond, Nick Stang, Ken Winkler, an anonymous referee for this journal, and participants of the Dutch Seminar in Early Modern Philosophy and the History of Early Modern Philosophy Working Group at the University of Toronto for feedback on earlier versions of this paper. 